\title{
Os dois teatros
}

O presente artigo, publicado no Japão em $2011^{2}$, foi produzido a partir de uma palestra ministrada na Universidade de Waseda, no dia 14 de dezembro de 2007, para o grupo de pesquisa/tradução da obra Qu'est-ce que le théâtre ? ("O que é o teatro?") de Christian Biet e Christophe Triau ${ }^{3}$.

\section{Retrospectiva: do "teatro amador" ao "teatro dos amadores"}

Quando demos início à presente reflexão, em 1998, havia na França uma imagem bastante negativa do teatro dito "amador". Ele era visto como uma forma degradada, como uma pálida cópia do teatro profissional. Essa imagem era em parte fundamentada na definição jurídica deste último, formulada recentemente, em um decreto de dezembro de 1953. Esse texto havia sido elaborado em um contexto muito particular, que analisamos a seguir: no período imediatamente após a guerra, as profissões do espetáculo se reoganizaram. Elas se redefiniram pela diferença, ou até mesmo pela oposição, às práticas dos amadores, em plena efervescência na época, A palavra "amador", que até então era um substantivo - soberbo e elogioso (denotando 'aquele que aprecia uma arte e, eventualmente, a pratica'), mesmo que a conotação de incompetência já existisse há muito tempo - se tornou um adjetivo, sinônimo de não-profissional. Pela primeira vez na história, essa prática livre, plenamente difundida, do fazer teatral e da representação em público, era definida negativamente, ou seja, definida pelo que ela não era. Os redatores do decreto de 1953, que aspiravam aprimorar e apoiar essa atividade, como o faziam as associações de educação popular, contribu-

\footnotetext{
${ }^{1}$ ARIAS/CNRS (Laboratório de Pesquisa em Intermidialidade e Artes do Espetáculo do Centro Nacional de Pesquisa Científica, França)

${ }^{2}$ MERVANT-ROUX, Marie-Madeleine. "Les deux théâtres", in: Theatre and Film Studies 2010, International Institute for Education and Research in Theatre and Film Arts Global, Waseda University, Vol 5, 2011, pp. 159-176.

${ }^{3}$ Obra não publicada no Brasil. Referência da obra original : BIET, Christophe e TRIAU, Christophe. Qu'est-ce que le théâtre ?. Paris : Gallimard, 2006. Coleção « Folio Essais ».
} 
íram, na realidade, para sua desvalorização, mantendo somente o critério econômico para defini-lo; nesse texto o que caracteriza de fato o grupo amador juridicamente é que ele não é remunerado. Nosso primeiro trabalho, fundado nas observações e nas experiências pessoais dos participantes, consistiu em propor e verificar uma hipótese bem diferente: que o teatro dos amadores possui originalidade e autonomia. E foi procurando reconstituir sua gênese que encontrei o trabalho de Élie Konigson sobre o "caldeirão medieval"4 - segundo a expressão do jurista-antropólogo Pierre Legendre.

\subsection{Um dado histórico: os dois modos de desenvolvimento iniciais da função dramática}

Élie Konigson, diretor de pesquisas do Centro Nacional de Pesquisa Científica (CNRS, França), especialista em Idade Média e Renascimento, relacionou o desenvolvimento de uma importante vida teatral na Europa à existência, nas cidades pré-industriais ocidentais, de uma função que ele chama - seguindo os historiadores e especialistas em geografia humana - de "função dramática", que ele mostra ser estreitamente "associada às outras funções genéricas que são as funções de troca e de legislação5".

No período que ele estuda (séculos XIV e XV) e no campo europeu, ele distingue dois modos de desenvolvimento dessa função dramática:

- um teatro profissional, fundamentalmente itinerante, que é de imediato um teatro de ruptura em relação ao tecido social da urbe. Podemos ilustrar sua descrição pelo famoso exemplo da commedia dell'arte.

- um teatro amador (termo, em verdade, anacrônico, visto que essa noção só aparecerá bem mais tarde), que é um teatro de centro, de inscrição urbana, de reconhecimento recíproco entre atores ocasionais e espectadores, todos concidadãos. Ele possui um papel essencial na manutenção dos valores, das ordens sociais e dos códigos comuns. As Paixões encenadas (outro termo anacrônico) nas grandes cidades do norte da França ou da Suíça, estudadas por É. Konigson em muitas obras ${ }^{6}$, fazem parte dessa categoria.

\footnotetext{
${ }^{4}$ Nota da tradutora : A expressão original em francês é "creuset médieval", literalmente "cadinho medieval". ${ }^{5}$ Ver seu estudo: "Marges et lisières du jeu théâtral", in: Du théâtre amateur.Approche historique et anthropologique. Paris : CNRS Éditions, 2004, pp. 16-22.

6 "Milagres", a partir do século XIV, "mistérios" nos séculos XV e XVI e, provavelmente de formulação comparável no que diz respeito às relações com o espaço urbano ou doméstico e ao status dos intérpretes, os poucos raros fazeres teatrais não religiosos de associações civis do século XIII francês. Ver por exemplo: KONIGSON, Élie. "La place du Weinmarkt à Lucerne ; remarques sur l'organisation d'un espace dramatisé", in: Théâtre, Histoire, Modèles. Recherches sur les textes dramatiques et les spectacles du XVe au XVIII siècle, estudos reunidos
} 
Essa proposição, formulada de modo bastante claro em uma palestra para especialistas de teatro de rua ${ }^{7}$, chamou minha atenção: ela fornecia um início de resposta à questão da identidade do teatro amador moderno, eliminando um grande número de ideias preconcebidas. Ela se opunha à confusão generalizada, inclusive em meio a teatrólogos, entre teatro amador e teatro de feira. Os atores amadores das Paixões são evidentemente sedentários e, portanto, conhecidos por todos. Os errantes, às margens do teatro europeu moderno, são os profissionais. Na crítica dos mitos teatrais, É. Konigson vai assim ao encontro de um outro historiador, Ferdinando Taviani, autor de obras de referência sobre a commedia dell'arte:

\begin{abstract}
Por uma ironia da história, é justamente esse teatro fechado [a commedia dell'arte], produzido de modo bastante econômico por pequenos grupos, atentos às leis de mercado e capazes de combinar com uma grande habilidade profissional uma considerável repetitividade com uma aparente versatilidade de formas, esse teatro capaz de migrar para qualquer canto da Europa, que se revelou aos pesquisadores modernos (sobretudo e antes de tudo aos não-italianos) como o teatro mais popular de seu tempo, o mais coral, produto direto dos costumes e da mentalidade da praça pública, enraizado nos traços originais da cultura nacional italiana ${ }^{8}$.
\end{abstract}

\title{
1. 2. Dois grandes modelos antropológicos
}

A história esclarecia assim nossa reflexão sobre o presente. Encontramos primeiramente, em Élie Konigson, a ideia de um duplo desenvolvimento inicial do teatro europeu. Entre os fazeres teatrais locais (como os mistérios da Paixão, por exemplo), assumidos pelos patrícios das cidades, e as primeiras trupes profissionais, compostas por atores de verdade (organizadas no modelo da Commedia), não havia dois modos de fazer a mesma coisa, uma paga e a outra não, mas dois modos bem distintos de realização da função dramática. Também pudemos constatar que os traços essenciais da distinção original eram os que observávamos entre as realizações do amadorismo moderno e as companhias de profissionais contemporâneos. No caso dos espetáculos de amadores contemporâneos (ou dos mistérios), a atividade dramática não faz perder àquele que a exerce o seu status social; ela é, ao contrário, um modo de vivê-lo. Uma das consequências desse fato é que essa atividade em si não é, nesse caso, definida

\footnotetext{
e apresentados por É. Konigson. Les Voies de la création théâtrale, vol. VIII, Paris: Éditions du CNRS, 1980. Coleção: Arts du spectacle, pp. 43-90.

7 "Traditions et lisières", in: Les Rendez-vous de Lieux Publics, Marseille, 1993, pp. 14-17.

8 «Positions du masque dans la commedia dell'arte », in: Le Masque. Du rite au théâtre (dir. Odette Aslan et Denis Bablet), Paris: CNRS Éditions, 1985, p. 127.
} 
socialmente. A indefinição, ou seja, a ausência de status de ator amador como tal, a ausência para aquele que interpreta de uma ruptura franca com os códigos da sociedade, a ausência de uma inscrição franca na esfera estética, faz sua diferença real em relação à atividade, igualmente mimética e lúdica, praticada pelo ator profissional (tanto hoje como antigamente), pois este, interpretando, encarna de algum modo o teatro oficialmente. É evidente que essa diferença é de natureza antropológica e que ela não poderia ser reduzida a uma simples oposição entre lucrativo e não-lucrativo. Os efeitos disso são bastante impactantes no desempenho do teatro e da relação com os espectadores. O ator amador, por exemplo, não pode interpretar qualquer papel, pois sua figura social nunca desaparece de sua figura cênica, pelo menos do ponto de vista do público. Este, dedicando à cena apenas parte de seu tempo, não constrói metodicamente um corpo e um rosto específico para o teatro.

Além do que diz respeito ao indivíduo-ator, três traços maiores do "amadorismo" dramático primitivo encontram-se claramente refletidos nas manifestações contemporâneas do amador:

- as raízes sociais (não só através de praticantes cujo papel principal - como vimos - não é o de ser ator, mas também através de "comunidades de interpretação limitada" "que constituem suas plateias). Encontramo-nos em espaços privados, semiprivados, semipúblicos;

- a grande homogeneidade e frequente reversibilidade dos atores em espectadores e vice-versa;

- a predileção pela estrutura dramática, em relação ao trabalho especificamente cênico, característica de profissionais.

Desse modo, o que era um dado histórico se tornou uma matriz estrutural, ponto de partida de uma evolução dupla, que reconstituímos parcialmente, com duas formas de expressão dramática, dois tipos de espaço cênico (aspecto que desenvolveremos mais adiante), dois tipos de relação com o texto e com a ficção, dois tipos de interpretação. Começamos a perceber nas atuais práticas do amador, não a continuação direta do modo dramático pré-industrial, minuciosamente descrito por Élie Konigson, (a sociedade e a cidade mudaram. O primeiro amadorismo verdadeiro, o do Século das luzes, nasceu da secularização do modelo paralitúrgico), mas sim uma nova variação

\footnotetext{
${ }^{9}$ Expressão de Laurence Allard (aqui traduzida literalmente do francês: "communautés d'interprétation restreinte") em relação aos clubes de cineastas amadores.
} 
dessa outra organização do evento teatral, fundamentalmente diferente da mais familiar aos pesquisadores acadêmicos, organizada e ministrada por artesãos.

A lição principal dessa ida e volta entre passado e presente é teórica. E decisiva: não estamos em presença de um modelo teatral único, com uma forma pura e uma forma degradada, mas sim de dois modelos diferentes.

\subsection{A cena original dos amadores}

Agora podemos estudar as qualidades em si de um teatro que já foi dito "sem qualidades.' Recentemente, dedicou-se, na França, uma pesquisa à sua dimensão estética. A expressão dramática amadora adquiriu de fato características próprias com o tempo, das quais algumas foram descritas e analisadas ao longo de nosso estudo. Ela estabeleceu progressivamente um repertório específico (muitas comédias, teatro narrativo, teatro "para dizer"...); ela se organizou segundo os ritmos temporais que não correspondiam à "temporada" profissional (o grupo amador ensaiava - ainda ensaia - no inverno e apresenta no verão); ela se dispersou em salas e lugares díspares constituindo espécies de margens internas na sociedade, esses espaços de representação se mostram verdadeiros espaços marginais (desenvolveremos este ponto adiante). A noção de "margem interna" é importante: se o adjetivo "interno" sublinha a ausência de ruptura com os códigos sociais, o substantivo "margem" restitui a função lúdica e "distanciadora" do teatro, inclusive do teatro amador. É realmente necessário, contra uma tendência sempre recorrente, não identificar o teatro dos amadores, inclusive o mais antigo, com um teatro de festas, procissões, desfiles e quermesses simpáticas. Nem com uma cena consensual. Uma produção amadora pode ser perfeitamente transgressiva, mesmo que a estrutura na qual ela se inscreva, como vimos, não o seja.

Para concluir esta primeira explanação: fazer teatro como amador não é fazer o mesmo teatro que os profissionais, só que gratuitamente e mais canhestramente. É, sem dúvida, ter menos proficiência pois, estatisticamente, a experiência é bem menor. É, sem dúvida, não viver disso e nem mesmo tentá-lo. Mas a diferença crucial diz respeito à natureza do cenário onde se dão as apresentações, sem ruptura com a cena social. Para os praticantes, é uma perspectiva bem diferente. A ideia regularmente emitida nos relatórios departamentais desde os anos 90 , segundo a qual os dois teatros desembocariam um no outro, como "vasos comunicantes", despejando 
magicamente no frasco dos amadores o transbordamento de atores profissionais (desempregados), comprova uma ignorância de suas duas especificidades.

Pudemos chegar a este resultado porque nossa abordagem se baseou inicialmente na etnografia (observação, práticas, estudos de campo, análise de arquivos locais, incluindo análises de discurso e de identificação), complementada pela antropologia histórica praticada por Élie Konigson, mas também pelo momento decisivo que foi o século XVIII, segundo Martine de Rougemont ou Marie-Emmanuelle Plagnol-Diéval. Pudemos, desse modo, tomar uma distância crítica em relaçao às abordagens sociológicas, as únicas existentes no domínio do amadorismo, que não colocavam à prova nem a definição oficial do teatro dito "amador", nem as imagens dadas. Elas foram, ao contrário, reforçadas por elas.

\section{Lugares e espaços dos dois teatros}

Referindo-nos à abordagem semiológica de Anne Ubersfeld, definiremos "lugar" como um "elemento concreto topologicamente determinável." O "espaço teatral" é um edifício, sala ou um terreno equipado, ao ar livre, "geralmente urbano", no qual se situa o "lugar cênico", palco construído ou simples espaço cênico. "Espaço" é uma "categoria genérica abstrata". Diferencia-se o "espaço cênico," "organizado simbolicamente", do "espaço do jogo"10 (do ponto de vista do ator) e do "espaço dramático" (do ponto de vista do espectador), ou seja, o espaço "no qual se acredita", ligado à "ficção fundamental.' As expressões "espaço dramático" e "espaço teatral" são intercambiáveis nesse contexto.

\subsection{A geografia do teatro amador}

Atualmente, como no passado, os edifícios (e de um modo geral os lugares) onde se desenvolve o teatro amador, com exceções em alguns contextos, não são os mesmos onde se desenvolve o teatro profissional. Em várias pesquisas recentes, as vistorias regionais ou departamentais encomendadas pelo Gabinete de Práticas Amadoras do Ministério da Cultura e da Comunicação ${ }^{11}$ vão na mesma direção. Em Paris, cidade onde a implantação histórica das salas de espetáculo é de conhecimento geral, pode-se falar de um arquipélago teatral amador invisível, de uma rede de locais de ensaio e de apresentação praticamente desconsiderados pelo mundo profissional e por seus espec-

\footnotetext{
10 Nota da tradutora : "Espace de jeu" é ambíguo em francês, pois o termo "jeu" pode ser entendido neste contexto como "jogo" ou "interpretação".

${ }^{11}$ Gabinete criado em 1998 pela Ministra da Cultura da época, Catherine Trautmann.
} 
tadores. O mesmo ocorre em toda a França. Frédéric Fisbach conta que, tendo escolhido há alguns anos coordenar cursos para amadores no Departamento da Creuse - cursos de onde sairia a montagem de "O anúncio feito a Maria" (texto de Paul Claudel), misturando atores profissionais e coristas amadores -, descobriu uma cartografia cultural cuja existência ele nunca suspeitara. Em grandes cidades ou vilarejos, os lugares que acolhem as práticas amadoras são quase sempre modestos: salões de festas, centros comunitários, propriedades rurais, espaços de associações (semiprivados, semipúblicos), escolas, propriedades privadas, ginásios de esportes, pequenos teatros...

O conjunto desses dados confirma a inscrição da vida teatral do amador nos recônditos da vida social, o que constitui, como vimos, uma diferença fundamental em relação à vida teatral profissional, cujos edifícios, ou abrigos, possuem um certo status à parte na cidade. No entanto - e chegamos aqui ao cerne de nosso processo de esclarecimento -, mesmo se os lugares concretos utilizados pelas apresentações amadoras fossem os mesmos dos profissionais (como é o caso às vezes), eles não funcionariam simbolicamente do mesmo modo. Os "espaços" desses dois teatros não são idênticos. Esse ponto merece que tomemos o tempo devido para esclarecê-lo: a diferença pode parecer sutil, e aqueles que nunca tiveram a experiência pessoal de assistir a uma sessão teatral de amadores podem não percebê-la ou julgá-la irrisória, coisa que ela não é.

Voltemos primeiramente ao equívoco generalizado que apenas havíamos evocado rapidamente até aqui: o que distingue fundamentalmente os dois teatros não é de natureza econômica. Quando falamos de um funcionamento simbólico variável dos espaços, não pretendemos sugerir a oposição binária clássica entre sistema de mercado e sistema de dom, entre um mundo onde se paga seu ingresso e um mundo onde se tem acesso ao espetáculo gratuitamente, com o que isso, para o segundo, implica sociabilidade, proximidade e comunhão espontânea. A primeira razão é que a realidade, presente e passada, do teatro de amadores não corresponde a essa imagem mitológica: se, de fato, os atores não são pagos pessoalmente, esse teatro não é imune às leis econômicas e, precisamente, o público contribui muitas vezes com alguma quantia com as despesas assumidas pelo grupo. Para voltar à História e aos trabalhos dos historiadores, ao contrário da lenda, os espetáculos medievais e renascentistas não-profissionais eram pagos. As tabelas de preços encontradas atestam até mesmo a existência de uma gradação precisa do custo dependendo do lugar ocupado, 
à qual os pobres de verdade não tinham acesso ${ }^{12}$. Esse lembrete é importante. $\mathrm{O}$ sonho de uma cena medieval popular e gratuita é comparável ao clichê atual segundo o qual a não-lucratividade constitui o critério decisivo para a definição da prática do amador. O que, como acabamos de expor, é falso.

A verdadeira diferença "simbólica" entre o funcionamento da cena profissional e da cena amadora está ligada ao lugar assumido em cada caso pelo espectador. Sua principal função continua a mesma: ele contribui para a constituição do lugar cênico em espaço dramático, ele "acredita", ele "faz como se." Que a produção seja amadora ou profissional, a casa do "Caprichos do amor e do acaso" (de Marivaux) ou a paisagem mental de "Esperando Godot" (de Samuel Beckett) serão igualmente "co-imaginadas" por aquele que assiste o espetáculo. É a relação entre o "espaço dramático" do espectador e o "espaço do jogo" do ator que se organiza de modo diferente. $\mathrm{Na}$ análise minuciosa de Anne Ubersfeld, o estudo do teatro amador faz surgir a necessidade de um novo estrato de análise suplementar, envolvendo a relação entre o público e o jogo dos atores. Para chegar a isso, proponho que recorramos à noção de "espaço teatral", redefinida como "espaço palco-platéia", incluindo as interações entre os dois polos da representação e suas respectivas ligações com a cidade. É neste ponto que nos deparamos com a dupla noção de "teatro de palco" e "teatro de tablado".

\section{2. O palco e o tablado. Do descritivo ao estrutural}

Para entender a natureza da variação que afeta o funcionamento simbólico do espaço teatral quando se trata de uma produção de amadores ou de profissionais, optamos por usar a oposição sugestiva de duas imagens: o "palco" inicial dos mistérios (a autora sublinha que a palavra "plateau" - aqui traduzida como "palco" - está sendo utilizada no seu sentido medieval de plateia e não no sentido moderno, ou pós-moderno, inspirado pelo cinema ou pela televisão) ${ }^{13}$ e o tablado inicial dos espetáculos itinerantes (a palavra "tablado" ["tréteau"] tendo seu sentido de estrado mínimo) ${ }^{14}$.

\footnotetext{
12 Ver por exemplo: KONIGSON, Élie. L'Espace théâtral médiéval. Paris: Éditions du CNRS, 1975.

13 "'Plateau' (aqui traduzido como "palco") - C. ARTES DO ESPETÁCULO. 1. TEATRO. Entabuamento elevado sobre o qual os atores interpretam e os cenários são colocados." TLF (Trésor de la langue française), CNRS (online).

14 "Tréteau (aqui traduzido como "tablado") - No sing. a) Plataforma elevada em relação ao nível do chão, sobre a qual exibia-se um condenado. Sinôn. cadafalso [.... . b) Plataforma móvel sobre a qual se produzia um número de 'vendedorde-banha-de-cobra', um artista ou uma trupe apresentando um espetáculo popular. Sinôn. estrado. [...]". Idem.

2. Plur., ger. pejorativo. Plataforma rudimentar utilizada por artistas de feira, atores representando peças populares. Comédien de tréteaux. (lit. ator de tablado) Ibidem.
} 
Devo inicialmente indicar que Élie Konigson nunca fala de "teatro de tablado" nem de "teatro de palco" e ainda menos de uma oposição significativa entre duas teatralidades, já que essa questão não faz parte de seu campo de pesquisa. O que consta em seus escritos é a comparação entre os dois objetos, enunciada uma única vez (até onde temos conhecimento), em uma nota de rodapé do estudo redigido por nossa obra "Du théâtre amateur": "Nota-se, para as apresentações urbanas, a oposição entre os espaços no nível do chão da praça, com plataformas de apresentação, por definição estáveis e imóveis, e o espaço do tablado, feito para a viagem e para a trupe itinerante. ${ }^{15 "}$ Em todos os outros lugares, as evocações estão separadas. E claramente assimétricas. O "tablado" ("tréteau") aparece em muitos escritos do autor nos quais ele parece ter sido frequentemente uma fonte de inspiração. Nas obras e artigos de tipo histórico ${ }^{16}$, ele designa um estrado, com ou sem cortina, elevado como um cadafalso para que o público veja bem os atores. "É um espaço suspeito, preocupante, onde o ser é apenas falsidade ou morte. A conjunção entre o cadafalso e o estrado não está somente na forma: esses dois espaços evocam um ao outro, se atraem. ${ }^{17 "} \mathrm{Em}$ certos textos mais recentes, onde a abordagem se faz estruturalista, o tablado se torna um dos três "objetos de representação" genéricas do teatro ocidental, os dois outros sendo a cortina e a sedes ${ }^{18}$. Encontra-se bem raramente a palavra "palco" ("plateau"). Essa tradução do termo latino plateia designa um tipo de passarela, larga e baixa, construída nas praças para servir de suporte para certas sequências das Paixões, a apresentação acontecendo em um espaço bem mais largo, no nível do chão. Se o tablado é dotado de uma função representativa genérica - ele significa por si só o teatro -, o palco aparece somente em um contexto de expressão dramática amadora. Ele se inscreve em um conjunto de outros elementos que contribuem para significar os lugares fictícios sucessivos ou simultâneos. O espaço teatral é a praça inteira convém notar que ela é fechada, e de alguma forma «privatizada» para a duração das apresentações: "O cidadão-ator, quando seu papel não o envolve na ação representada, vai sentar indistintamente na frente de seus concidadãos espectadores. Em suma, essa unidade espacial também define uma unidade que é, acima de tudo, uma

\footnotetext{
15 « Marges et lisières du jeu théâtral », nota 3, Du théâtre amateur, op. cit., p. 17.

${ }^{16}$ Como L’Espace théâtral médiéval, op. cit.

17 « Marges et lisières du jeu théâtral », loc. cit., p. 19.

${ }^{18} \mathrm{KONIGSON}$, Élie. "Les objets de représentation au théâtre (XVe-XVII siècles) ", in: Nouvelle Revue du Seizième Siècle, 1996, n 14/2, pp. 189-199.
} 
recusa, uma negação visível de uma mudança de status que o fazer teatral poderia, pelo menos, sugerir ${ }^{19}$ ".

Nossa contribuição consistiu em estender a oposição esboçada por Élie Konigson entre o tablado portátil dos ambulantes e o palco pesado dos sedentários, partindo das realidades concretas (os lugares) às construções abstratas (os espaços) e em fazer a distinção material, visível, entre as duas plataformas cênicas localizadas no tempo, uma alegoria da diferença de tempo entre dois sistemas de trans-históricos: um primeiro sistema onde os atores forasteiros dão origem a uma alteridade radical a partir de seu tablado ${ }^{20}$, uma verdadeira "máquina de viajar no espaço e no tempo" (É. Konigson), diante dos espectadores, que serão os transmissores desse evento na cidade; um segundo sistema em que alguns membros da cidade, em cima dessas espécies de palcos instalados no lugar onde eles vivem ou não muito longe de onde eles vivem, se tornando momentaneamente atores na frente de outros membros da urbe, que se tornam temporariamente espectadores. Ambas as descrições genéricas permanecem válidas independentemente do tipo de plataforma escolhida para a representação, independentemente do tipo de lugar utilizado. Nas expressões "teatro de palco" e "teatro de tablado", o palco e o tablado adquirem um valor alegórico. Na medida em que um verdadeiro tablado (ou qualquer dispositivo cênico profissional moderno), usado para uma apresentação de amadores, sempre acaba funcionando como palco genérico, e um verdadeiro palco (ou qualquer modesto estrado de amadores) utilizado por um grupo profissional se verá dotado do mesmo valor que o tablado original - e isso para melhor ou para pior, porque esses dotes simbólicos não prejudicam o talento de ambos. É o que vamos ver agora em dois exemplos franceses recentes escolhidos por sua complementaridade: um espetáculo profissional que desceu de seu pedestal cênico, e uma apresentação de amadores em um belo palco.

\section{3. $A$ « oficina » dos profissionais / o « verdadeiro » teatro de amadores}

Vamos descobrir rapidamente estes dois espetáculos.

a) Uma "Fedra" profissional que renunciou ao Teatro

“Em 1995, no fim dos ensaios de "Na solidão dos campos de algodão", a figurinista Moidele Bickel diz a Patrice Chéreau : Agora você tem que montar Racine, e do

\footnotetext{
19 «Marges et lisières du jeu théâtral », loc. cit., p. 18.

${ }^{20}$ Nota da tradutora: Aqui existe uma ambiguidade criada pela palavra "scène", que significa "cena" e, ao mesmo tempo, é uma palavra que designa qualquer plataforma destinada à representação teatral. Neste contexto, ela pode ser interpretada como "tablado" ou "cena".
} 
mesmo jeito', precisando que a sua missão agora era a de explorar a língua de Racine "desse jeito". O convite, justamente por ser tão enigmático, não seria esquecido facilmente; relendo Racine, Chereau foi percebendo que sentido esse convite passava a adquirir para ele. A travessia da obra de Koltès talvez o tivesse preparado para decifrar, na clareza dos encadeamentos sintáticos, o medo do outro lado da linguagem, fugaz, escondido, indizível, só que fadado a insistentemente ir abrindo brechas rumo à luz. ${ }^{21}$ ".

Alguns anos mais tarde, Patrice Chéreau decide montar "Fedra". O encenador reuniu Pascal Greggory (Teseu), Eric Ruf (Hipólito), Michelle Marquais (Enone), Michel Duchaussoy (Terâmenes), Marina Hands (Arícia), Agnès Sourdillon e Nathalie Bécue. Ele confiou a Dominique Blanc, depois de anos de trabalho juntos, o papel de Fedra. E é num lugar e cenografia extremamente próximos ao espaço e cenografia que utilizara em sua "Solidão..." que escolheu inscrever a tragédia de Racine. 0 espetáculo foi criado em Paris em 2003. O lugar? Os antigos depósitos de cenário da Opéra Comique, no norte da capital francesa, boulevard Berthier, convertido em uma sala de espetáculo modulável com cerca de 500 lugares durante as longas reformas do Théâtre de l'Odéon. Mesmo confortavelmente mobiliados, tanto no palco como na platéia, os "Ateliers Bethier" - assemelhando-se a galpões de oficina como a sala reformada do Théâtre des Amandiers de Nanterre, escolhida em 1987 para a criação da peça de Koltès (com Laurent Mallet e Isaach de Bankole) ou com a da Manufacture des CEillets, utilizada em 2005 para a última temporada do espetáculo (com P. Chéreau e P. Greggory) - pareciam salas transformáveis, vazias, neutras, funcionais. A cenografia? um dispositivo bi-frontal construído por Richard Peduzzi no mesmo registro que o da "Solidão...": proximidade, intensidade, dissimetria, torção perceptiva. As filas de poltronas estão frente a frente, dispostas ao longo de uma pistra central estreita incessantemente percorrida pelos atores com, em um extremidade, uma muralha atravessada por uma porta antiga, e, do outro lado, a nebulosidade de uma espécie de passagem aberta, um lugar de espera, algumas cadeiras colocadas lá, viradas para a cena.

O desejo de diminuir a distância com o público se manifesta desde a primeira cena. Terâmenes e Hipólito surgem do meio da plateia, Hipólito conta as façanhas de seu pai sentado no meio dos espectadores, nos degraus do corredor da plateia, em contato direto com seus vizinhos imediatos. Sem elevação, sem separação física,

${ }^{21}$ LOAZA, Daniel. Fragmento do livro de imprensa do espetáculo. 
nenhum dos sinais cenográficos habituais da "máquina de viajar no espaço e no tempo." Sem "tablado." Pelo menos aparentemente.

b) Um "Caprichos do amor..." amador representado "como no teatro"

A última seqüência do filme de Abdellatif Kechiche, "A Esquiva", lançado em janeiro de 2004 (e premiado com vários Césares em 2005), mostra um pequeno espetáculo de amadores - ou melhor, um espetáculo cujo status é difícil de definir, algo entre produção escolar e espetáculo de amadores. É o último episódio de uma história complexa, contada pelo produtor da seguinte forma:

\begin{abstract}
Um conjunto habitacional na perferia de Paris. Um anjo passa recitando com entusiasmo os versos de "Caprichos do amor e do acaso". É Lídia (Sara Forestier), apaixonada por Marivaux, em pleno ensaio do espetáculo montado por sua classe para a festa da escola. Passou um anjo, e Abdelkrim, vulgo Krimo (Osman Elkharraz), no auge dos seus 15 anos, está gostando de sua colega de classe. Ele, que arrasta seu tédio pelos labirintos do bairro, acompanhado por seus amigos, de repente, descobre o amor. Krimo não é de muita conversa e tem uma reputação a zelar: como declarar seu amor para a garota sem cair no ridículo? A solução: subornar seu amigo Rachid, parceiro de cena de Lídia, para fazer o papel de Arlequim. O que Krimo não ousa confessar, Marivaux fará em seu lugar! Mas a manobra inteligente se transforma em uma corrida de obstáculos para Krimo, petrificado pelo tamanho do texto e pela professora extremamente exigente. Será que Krimo encontrará as palavras certas antes que o boato, os ciúmes e as inimizades se intrometam na partida? ${ }^{22}$
\end{abstract}

Depois de algumas peripécias, às vezes dramáticas, ocorre a apresentação, sem Krimo, substituído pelo primeiro Arlequim. A representação volta ao contexto pedagógico (a professora sopra o texto dos bastidores), mas não está restrita a ele: o bairro inteiro está no centro comunitário onde o espetáculo é realizado.

"A Esquiva" foi, muitas vezes, comentado como um documentário, mas não é. Apesar de a maioria dos atores não ser de profissionais, apesar de Abdellatif Kechiche ter filmado em um conjunto habitacional de periferia real, sua abordagem não é etnográfica e ele faz questão de deixar isso claro. O consenso geral diz que o filme possui a verdade da ficção, sobretudo na área que nos interessa, o que me permite apresentá-lo como uma ilustração possível do fenômeno amador hoje. "A Esquiva" mostra o início tão rápido quanto doloroso, sob o influxo de desejos despertados pela escola, de uma espécie de "círculo" único dentro do bairro, de uma "sociedade" juvenil muito diferente dos grupos e gangues existentes. A festa final, com a participação de muitos adultos do bairro, apresenta na sequência um conto, "A Conferência dos Pássaros", interpretado por crianças, e a peça de Marivaux, representada por adolescentes. A

\footnotetext{
22 Dossier de imprensa do filme.
} 
história dançada pelas crianças, recebida com emoção pelos pais e professores, é seguida pelo texto de Marivaux, imediatamente percebido como mais difícil (os rostos dos espectadores exprimem uma atenção bem diferente, os eventuais risos serão uma vitória), uma apresentação na qual os múltiplos contextos individuais e coletivos são bastante perceptíveis: a câmera mostra Magali várias vezes com seu novo amante, Fahti e os outros garotos no fundo da sala, Krimo do lado de fora, atrás do vidro. Enquanto a história coreografada inspira uma adesão fácil, as frases aparentemente inofensivas de "Caprichos do amor e do acaso" são carregadas pela tempestuosa história do grupo cujos membros estão todos presentes. Sente-se claramente a tensão entre o teatro e a comunidade.

\section{4. « Estrutura aparente » e estrutura de base}

No funcionamento de uma sociedade, instituição ou fenômeno cultural, um modo superficial de organização pode ser considerado como aquilo que estrutura realmente essa sociedade, instituição ou fenômeno cultural. Esses modelos artificiais "se interpõem como obstáculos entre o observador e seu objeto"23.

Vamos rever cada um dos exemplos. No caso de "Fedra", o desaparecimeto dos signos teatrais, o compartilhamento do espaço, o nivelamento do palco com a plateia, a proximidade excepcional, tudo isso só reforça o sentimento de uma ruptura absoluta entre o público e "espaço de jogo" dos atores (onde se encontram Eric Ruf, Dominique Blanc, Marina Hands...) de um lado e o espaço dramático (ao qual assombram Fedra, Hipólito, Arícia...) do outro. Para os espectadores que se pode observar enquanto eles escutam os atores falar na gravação audiovisual, para aquele que podemos observar quando Éric Ruf-Hipólito vem intalar-se ao seu lado, o tablado simbólico está mais do que nunca presente.

No caso do Marivaux de "A Esquiva", o fato de que o espetáculo esteja sendo apresentado em uma plataforma cênica elevada, em um dispositivo frontal clássico e seguindo as regras tradicionais da sessão de teatro não altera os fenômenos característicos do que chamamos de "teatro de palco": essas condições de representação conferem uma espécie de solenidade ao evento, mas como os espectadores conhecem todos os intérpretes, ou sentem que poderiam conhecê-los, o entrelaçamento do real com a ação dramática se dá continuamente em ambos os lados da fronteira entre espaço cênico e

${ }^{23}$ LÉVI-STRAUSS, Claude. Anthropologie structurale. Paris, Plon, Presses Pocket, 1974, p. 335 (1 ${ }^{\text {re }}$ éd. 1958). 
auditório. A vida real dos atores se mistura com a ficção. Os espectadores o percebem e acompanham ao mesmo tempo, em outro nível, a atuação frágil de jovens cuja "proficiência" não é garantida. Todos estão conscientes: esse ator, essa atriz, "poderia ser ele [ou ela] mesmo[a]", ou algum conhecido. Pode-se falar de um funcionamento original da mimesis: porque aquele que interpreta ainda é percebido em sua atividade excepcional de ator, o épico é estrutural, a distanciação, permanente. A universalidade da expressão não desaparece, é, pelo contrário, vivida através de uma série de conotações e interpretações locais, interpessoais, privadas, que podem enriquecê-la.

Em Berthier - a qualidade de antiga oficina desse lugar não altera o caso -, o público é recebido em um espaço artístico, claramente extraído do espaço social comum. O lugar todo é "teatralizado". No centro cultural de "A Esquiva", um lugar cênico foi inserido sem que esse lugar - que pretende ser cultural - crie uma ruptura com a comunidade ${ }^{24}$. Tanto os espectadores como os atores estão em uma situação intermediária, que dão outro colorido ao evento teatral.

\section{Para concluir. Uma sutil complementaridade}

Explica-se a atual vitalidade do teatro de amadores na França por seu modo de inscrição na vida social. Encontra-se, às vezes, a hipótese (e a esperança) de uma reconstituição do teatro público a partir de seus muitos locais "semipúblicos", em uma espécie de remake da grande dinâmica descrita por Habermas (a emergência da "esfera política pública" a partir do imaginário literário e privado). Sugerimos em outro lugar que isso era um chamariz ${ }^{25}$. E é muito provavelmente indesejável também: manter, promover a variedade de espaços, inclusive os espaços privados e semiprivados, é de grande interesse. Esclareçamos esse ponto com uma comparação. Os especialistas da filosofia e da libertinagem do século XVII trabalharam sobre o modelo proposto por Habermas. Eles se deram conta, pelo menos para o campo deles, do simplismo desse modelo progressista e inequívoco, já que os libertinos mantiveram uma relação complexa com a abertura ao "grande público" e têm sustentado práticas sobre as quais o mínimo que se pode dizer é que elas não iam no sentido da futura transparência "comunicacional"26. Os espaços de debate e desenvolvimento de novas ideias tendem

\footnotetext{
${ }^{24}$ Nota da tradutora: No original, "cité", ao mesmo tempo "urbe" e "conjunto habitacional / bairro pobre".

25 MERVANT-ROUX, Marie-Madeleine. «Conclusion » da obra Du théâtre amateur. Approche historique et anthropologique, op. cit., pp. 345-347.

${ }^{26}$ Ver « Libertinage et philosophie au XVIIe siècle-3. Le Public et le Privé ». [Journée d'étude organisée par A.
} 
a permanecer fora da universidade e continuam a se organizar no modelo da conversa ou correspondência entre amigos de confiança. No contexto atual, como naqueles estudados por historiadores, por razões diferentes, é claro - o conservadorismo do pensamento não se organiza mais do mesmo modo, - e os lugares de reflexão e de expressão de natureza privada parecem preciosos, insubstituíveis na democracia. $\mathrm{E}$ isso vale também para a vida do teatro amador. Pudemos nos preocupar recentemente com o desaparecimento dos grupos estruturados como outrora, surgidos em associações - portanto, em uma esfera semipública. Seu desaparecimento é interpretado como um sinal do enfraquecimento da dimensão coletiva, muito importante no teatro amador. Constata-se que há algum tempo novos grupos têm emergido por afinidades eletivas, por reuniões entre indivíduos, em uma versão modernizada do "amigável" primitivo. Na contracorrente do processo que agora ameaça a individualização da prática do amador pelos "workshops", que se proliferam por toda parte, transmitindo modelos profissionais (ou pseudoprofissionais), reaparecem, a partir de núcleos claramente privados ou semiprivados, o que era antes chamado, em um termo bonito e significativo, "sociedades".

Quanto aos profissionais, como evidenciado pelo panorama de Hans-Thies Lehmann, mas também indiretamente por todos os estudos recentes sobre a cenografia e estudos de espaços para o teatro, os criadores muitas vezes se sentem bem melhor em salas que mantêm algo de "não público": seja dentro de teatros, em locais geralmente fechados para o público - tais como salas de ensaio, etc. - seja fora, em lugares que gostamos de enfatizar que não são projetados para o teatro (edifícios reciclados, museus, cafés, apartamentos...) mas que têm também a característica de não pertencer à esfera "pública" oficial. E quando o teatro (ainda é a situação mais frequente) se inscreve nessa esfera pública oficial, os artistas tentam, de dentro, paradoxalmente, "reprivatizar" - simbolicamente, é claro - o espaço de sua intervenção, e da representação.

O importante, em cada um desses dois teatros, parece-nos ser a mobilidade potencial do lugar, seu caráter intermediário.

Fala-se regularmente de uma necessidade sentida pela cena de conciliar-se com as novas sensações do espaço e do tempo. Há um modo superficial de se conciliar com esse movimento: fazendo espetáculos movimentados. É mais rico, mas mais complicado, levar em conta as novas relações da intimidade, da casa, da vida civil

McKenna et P.-F. Moreau], Publications de I'Université de Saint-Etienne, 1999. 
e política, os modos emergentes de fazer sociedade: dividir o espaço "privado" em espaços de acordo com casos semiprivados, semipúblicos; partir do semipúblico de novo em direção a um espaço que talvez possa se tornar verdadeiramente "público". Prestam-se a isso lugares percebidos como "transformáveis". Não se trata, não em primeiro lugar, de uma questão técnica.

Tradução: Rafaella Uhiara, doutoranda em Estudos Teatrais pela Université de la Sorbonne Nouvelle, sob a orientação de Marie-Madeleine Mervant-Roux. 